\title{
Transdisciplinarity and Sustainability
}

Conference Theme: Concepts and methods \& Institutional barriers and enablers

Glenn Albrecht

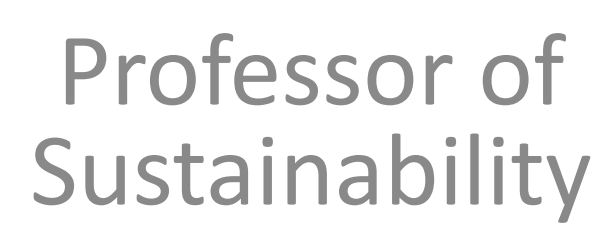

Murdoch University

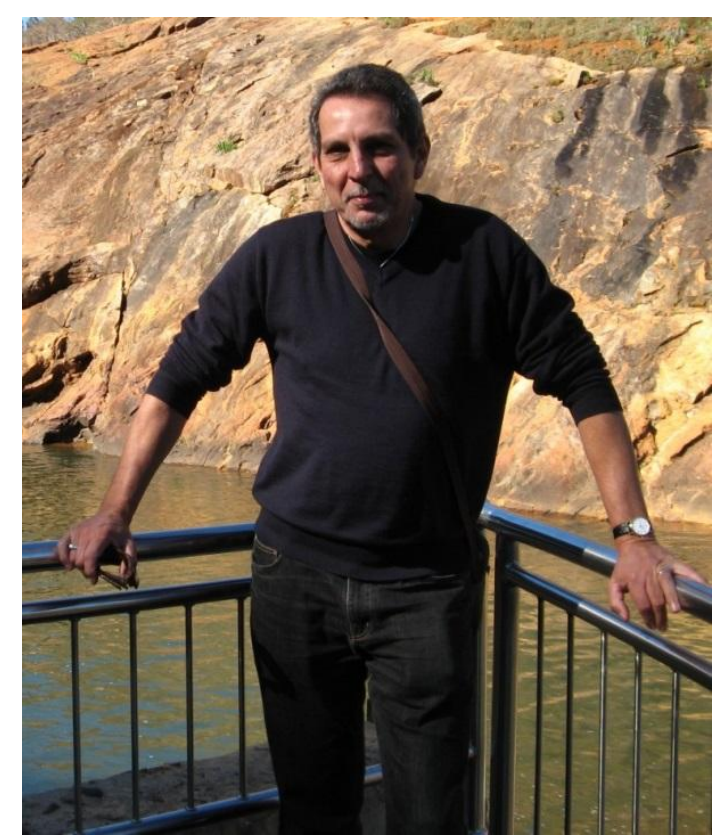




\section{Transdisciplinary Space}

"The transdisciplinary perspective assumes that (all) problems exist in what we might call 'transdisciplinary space'. Within this space are interactions between humans and their environment that range from deeply subjective and intersubjective to the impact of global climate change".

(Albrecht et al 1998:66) 


\section{Transdisciplinary Research}

- Sustainability academics produce and disseminate knowledge which transcends discipline boundaries

- Such transdisciplinary research and knowledge aims to integrate, amongst other things, sustainability science, ecologically and thermodynamically informed economics and normative ideas of equality and justice (across all generations and all species). 


\section{Not a proper discipline!}

- Yet transdisciplinary space and the transdisciplinary research paradigm is not recognised within the research quality frameworks and metrics that have become de rigour in the last decade

- The academic 'discipline' of seeing the interconnections between traditional disciplines and multiple fields of knowledge is accorded virtually no value because it does not fit comfortably within existing models of academic evaluation. 


\section{The Error of ERA}

- For example, in the Excellence in Research for Australia (ERA) and other metrics used to measure academic merit, sustainabilitydirected research has no place as it is not based on a traditionally defined discipline

- The ERA uses fields of research (FOR) codes based on disciplines to categorise and evaluate research. 


\section{Field of Research (FOR)}

- In Australia, the FOR is a hierarchical classification with three levels, namely Divisions (2 digits), Groups (4 digits) and Fields (6 digits). Each level is identified by a unique number.

- Each Division is based on a broad discipline. Groups within each Division are those which share the same broad methodology, techniques and/or perspective as others in the Division. 


\section{Does Not Exist!}

- Existing in an integrative and transdisciplinary space, sustainability cannot even be the reluctant owner of a discipline-based four digit Field of Research (FOR) code ... therefore, it does not exist in the world of university 'quality' and research rankings

- It must be categorised in the wilderness of 'not elsewhere classified' in research ... the kiss of death in grant applications. 


\section{Barriers}

- Australian universities are now supporting those research domains that have identifiable FOR codes that perform strongly in the discipline-based ERA evaluations of research quality

- As a result, individual or collaborative researchers who are committed to transdisciplinary research have little or no institutional support. 


\section{Rewarding Non-Sustainability}

- An illogical conclusion of this system of indicators is that there is virtually no institutional support for those who wish to contribute to

transdisciplinary sustainability-related research in a time of major ecological and climatic crises

- Yet, for example, discipline-based research funded by openly vested interests and directed at non-sustainable ends (greater use of fossil fuels) can count as most relevant in assessing research "excellence". 


\section{Rank Failure}

- In effect, what we are now ranking with instruments like the ERA and the Academic Ranking of World Universities (ARWU) is the achievement of non-sustainability

- As a consequence of the failure of ranking metrics to distinguish between sustainable and non-sustainable research means and ends, for example, student bodies all over the world are now demanding divestment of all forms of fossil fuel support at universities. 


\section{Adding to the FOR?}

- In NZ and Australia, recognition of the transdisciplinary nature of a research domain has been give to:

- Aboriginal and Torres Strait Islander Studies

- Maori Studies

- Pacific Peoples Studies

- I argue that Sustainability Studies is a transdisciplinary paradigm worth recognising as an integrative field of research in its own right. 


\section{Transdisciplinary Transformation}

- Unless major, transformative change under enlightened leadership takes place, the 21st century will be known as 'the Non-Sustainability Century'.

- Transdisciplinary sustainability is an easy concept to understand, it is made difficult only when we pay obsessive attention to metrics that count for nothing, and systematically ignore those integrative metrics that are vital to our collective future. 


\section{References}

Divestment: http://gofossilfree.org/

Greater use of fossil fuels. Graham Readfearn (2012) Expect Scepticism Over Gas IndustryFunded Research

http://www.readfearn.com/2012/11/expect-scepticism-over-gas-industry-funded-research/

Transdisciplinary Space. Albrecht, G., Higginbotham, N., Connor, L., and Freeman, S. (1998)

Complexity and human health: the case for a transdisciplinary paradigm. Cult Med Psychiatry. 1998 Mar;22(1):55-92. http://www.ncbi.nlm.nih.gov/pubmed/9657059

Transdisciplinary Research. Higginbotham, N., Albrecht, G and Connor, L. (2001) Health Social Science: A Transdisciplinary and Complexity Perspective. Oxford University Press.

http://catalogue.nla.gov.au/Record/2401534

Transdisciplinary Paradigm: Albrecht, Higginbotham, Connor and Freeman (1998) Complexity and human health: the case for a transdisciplinary paradigm.

http://www.ncbi.nlm.nih.gov/pubmed/9657059

Transformative Change. Geoff Scott, Daniella Tilbury, Leith Sharp, Elizabeth Deane (2012)

Turnaround Leadership for Sustainability in Higher Education, University of Western Sydney, Published: 2012.

http://www.olt.gov.au/resources/goodpractice?text=Turnaround\%20leadership\%20for\%20sustai nability\%20in\%20higher\%20education 


\section{Contact}

Glenn A Albrecht

Director: Institute for Social Sustainability

G.Albrecht@Murdoch.edu.au

healthearth.blogspot.com

@GlennAlb

(The First Global Conference on Research Integration and Implementation, http://www.I2Sconference.org/). 